\title{
The effect of growth hormone supplementation in poor ovarian responders undergoing IVF or ICSI: a meta- analysis of randomized controlled trials
}

\author{
Peiwen Yang, Ruxing Wu and Hanwang Zhang * (D)
}

\begin{abstract}
Purpose: The aim of this meta-analysis was to evaluate the effect of growth hormone (GH) supplementation in poor responders undergoing in vitro fertilization (IVF) or intracytoplasmic sperm injection (ICSI).

Methods: PubMed, MEDLINE and Cochrane Library databases were searched for the identification of relevant randomized controlled trials. Outcome measures were live birth rate, clinical pregnancy rate, miscarriage rate, cycle cancelation rate, number of retrieved oocytes and total dose of gonadotropin.

Results: Fifteen randomized controlled trails (RCTs) involving 1448 patients were eligible for the analysis. GH supplementation improved live birth rate $(\mathrm{RR}, 1.74 ; 95 \% \mathrm{Cl}, 1.19-2.54)$, clinical pregnancy rate (RR, 1.65; 95\% Cl, 1.31 2.08 ) and retrieved oocytes number (SMD, $0.72 ; 95 \% \mathrm{Cl}, 0.28-1.16)$, while reducing cancelled cycles rate (RR, $0.62 ; 95 \%$ $\mathrm{Cl}, 0.44-0.85)$ and dose of Gonadotropin (SMD,-1.05 95\% Cl, - 1.62 - -0.49) for poor ovarian response patients. Besides, there was no significant difference in the miscarriage rate between GH group and control group.

Conclusions: Based on the limited available evidence, growth hormone supplementation seems to improve IVF/ICSI outcomes for poor ovarian responders. Further randomized controlled trials with large sample sizes are required to clarify the effect of GH adjuvant therapy in the treatment of women with poor ovarian response.
\end{abstract}

Keywords: Growth hormone, Poor ovarian response, In vitro fertilization, Intracytoplasmic sperm injection

\section{Background}

Poor ovarian response (POR) is a condition that in a group of IVF and ICSI cycles, despite the appropriate ovarian stimulation, the number of oocytes collected is below the expected value [1].

POR presents approximately in $5-18 \%$ in all assisted reproductive technology (ART) cycles, with a pregnancy rate as low as $2-4 \%$ [2]. Therefore, POR is considered as one of the success-limiting factors for IVF/ICSI outcomes [3].

\footnotetext{
*Correspondence: hwzhang605@126.com

Reproductive Medicine Center, Tongji Hospital, Tongji Medical College, Huazhong University of Science and Technology, 1095 Jiefang Avenue, Wuhan 430030, People's Republic of China
}

The definition of POR has varied over time. In 2011, the European Society of Human Reproduction and Embryology (ESHRE) published the BOLOGNA criteria as a standardized definition. According to these criteria, poor responders are diagnosed with at least two of the three following criteria: 1 ) advanced maternal age ( $\geq 40$ years) or any other risk factor for POR, 2) a previously characterized POR cycle ( $\leq 3$ oocytes with a conventional stimulation protocol), 3) an abnormal ovarian reserve test (i.e. antral follicle count $<5-7$ follicles or AMH $<0.5-1.1 \mathrm{ng} /$ $\mathrm{mL}$ ) [4]. Various treatment including different stimulation protocols and adjuvant therapies have been applied to

C C The Author(s). 2020 Open Access This article is licensed under a Creative Commons Attribution 4.0 International License, which permits use, sharing, adaptation, distribution and reproduction in any medium or format, as long as you give appropriate credit to the original author(s) and the source, provide a link to the Creative Commons licence, and indicate if changes were made. The images or other third party material in this article are included in the article's Creative Commons licence, unless indicated otherwise in a credit line to the material. If material is not included in the article's Creative Commons licence and your intended use is not permitted by statutory regulation or exceeds the permitted use, you will need to obtain permission directly from the copyright holder. To view a copy of this licence, visit http://creativecommons.org/licenses/by/4.0/ The Creative Commons Public Domain Dedication waiver (http://creativecommons.org/publicdomain/zero/1.0/) applies to the data made available in this article, unless otherwise stated in a credit line to the data. 
Poor ovarian responders; however, the management of poor ovarian responders is still a clinical challenge.

Growth hormone is a peptide hormone secreted primarily by pituitary gland, and participates in cell growth, development and metabolism [5]. Growth hormone receptors (GHRs) have been shown to be expressed in ovarian granulosa, theca cells, oocytes, cumulus cells, mammary glands, placenta and uterus [6]. It is reported that $\mathrm{GH}$ raises ovary sensitivity to follicule-stimulating hormone (FSH) [7], regulates ovarian function [8], promotes follicular maturation [9], enhances proliferation of the thecal and granulosa cells [10], and improves follicular development [11]. GH has been applied in the treatment of infertility, especially for poor responders. Some studies showed that $\mathrm{GH}$ administration during ovarian stimulation can improve IVF/ICSI outcomes, such as oocyte quality, pregnancy rate, and live birth [12-14]. In 2010, a Cochrane review suggested that due to few number of RCTs and small sample size, the role of GH in IVF/ICSI needs further research [15]. In 2017, a metaanalysis done by $\mathrm{Li}$ et al. reported that the $\mathrm{GH}$ addition can significantly improve the clinical pregnancy rate and live birth rate. Since then, five new RCTs studying the influence of GH addition on IVF/ICSI outcomes have been published [16-20].

Therefore, the aim of this meta-analysis is to screen and extract RCTs and evaluate the use of GH for POR patients undergoing IVF/ICSI.

\section{Methods}

\section{Literature search strategy}

Two independent authors (PWY and RXW) performed a systematically search of the PubMed, MEDLINE and Cochrane Library databases for literature published covering the period until February 2020. The search strategy was performed by consecutively entering the following Medical Subject Headings (MeSH) terms and free word to generate subsets of studies: i) 'GH' or 'growth hormone', ii) 'Poor response' or 'low response', 'Diminished ovarian reserve' or 'Premature ovarian aging'. and iii) 'Randomized controlled trial' or 'RCTs'. These subsets were combined together by 'AND'. We also manually screened the reference lists of the retrieved articles to identify additional studies. No language limitations were applied.

\section{Eligibility criteria}

The inclusion criteria were:

(1) administration of growth hormone in the intervention;

(2) inclusion of women characterized as poor responders;
(3) inclusion of women undergoing IVF or ICSI, with any ovarian stimulation protocol;

(4) the selected articles were RCTs;

(5) a report of at least one of the following outcomes

1) Primary outcomes: live birth rate, clinical pregnancy rate

2) Secondary outcomes: miscarriage rate, cycle cancelation rate, number of retrieved oocytes, total dose of gonadotropin.

Secondary studies (i.e. systematic reviews, metaanalyses), and studies in which an additional drug was administered in conjunction with growth hormone were excluded.

\section{Data extraction and quality assessment}

Two reviewers (PWY and RXW) selected the studies independently and extracted data for each study; any disagreement between the two reviewers responsible for data extraction was resolved by discussion. The extracted data included the following: first author, publication year, study design, inclusion and exclusion criteria, number of participants, interventions, controlled ovarian hyperstimulation $(\mathrm{COH})$ protocols and outcomes (live birth rate, clinical pregnancy rate, miscarriage rate, cycle cancelation rate, number of oocyte retrieved, total dose of Gonadotropin). Articles were assessed for the risk of bias using the following parameters: random sequence generation, allocation concealment, blinding, incomplete outcome data, selective reporting and other bias.

\section{Statistical analysis}

The Revman 5.3 software (Cochrane Collaboration, Copenhagen) was used for meta-analysis. Dichotomous results were analyzed by calculating the relative risks (RRs) with 95\% confidence intervals (CIs). Continuous variables are expressed as the standardized mean differences (SMDs) with 95\% CIs. Meta-analysis were performed using fixed and random effect models based on heterogeneity. The heterogeneity between studies was evaluated with Cochran's Q and the $\mathrm{I}^{2}$ statistic, random effects model was performed if significant heterogeneity was identified between studies $\left(p<0.1, \mathrm{I}^{2}>50 \%\right)$. Otherwise, fixed effect model was applied. A funnel plot was used to evaluate publication bias.

\section{Results}

The search strategy yielded 691 studies in total. Of these, we excluded 43 duplicates, after reading the titles and abstracts, 618 irrelevant articles were excluded. Full copies of the 30 remaining studies were retrieved. 15 articles were excluded for the reasons described in Fig. 1. Only 15 studies fulfilled the selection criteria. Finally, we included 15 RCTs [14, 16-29], with a total of 1448 


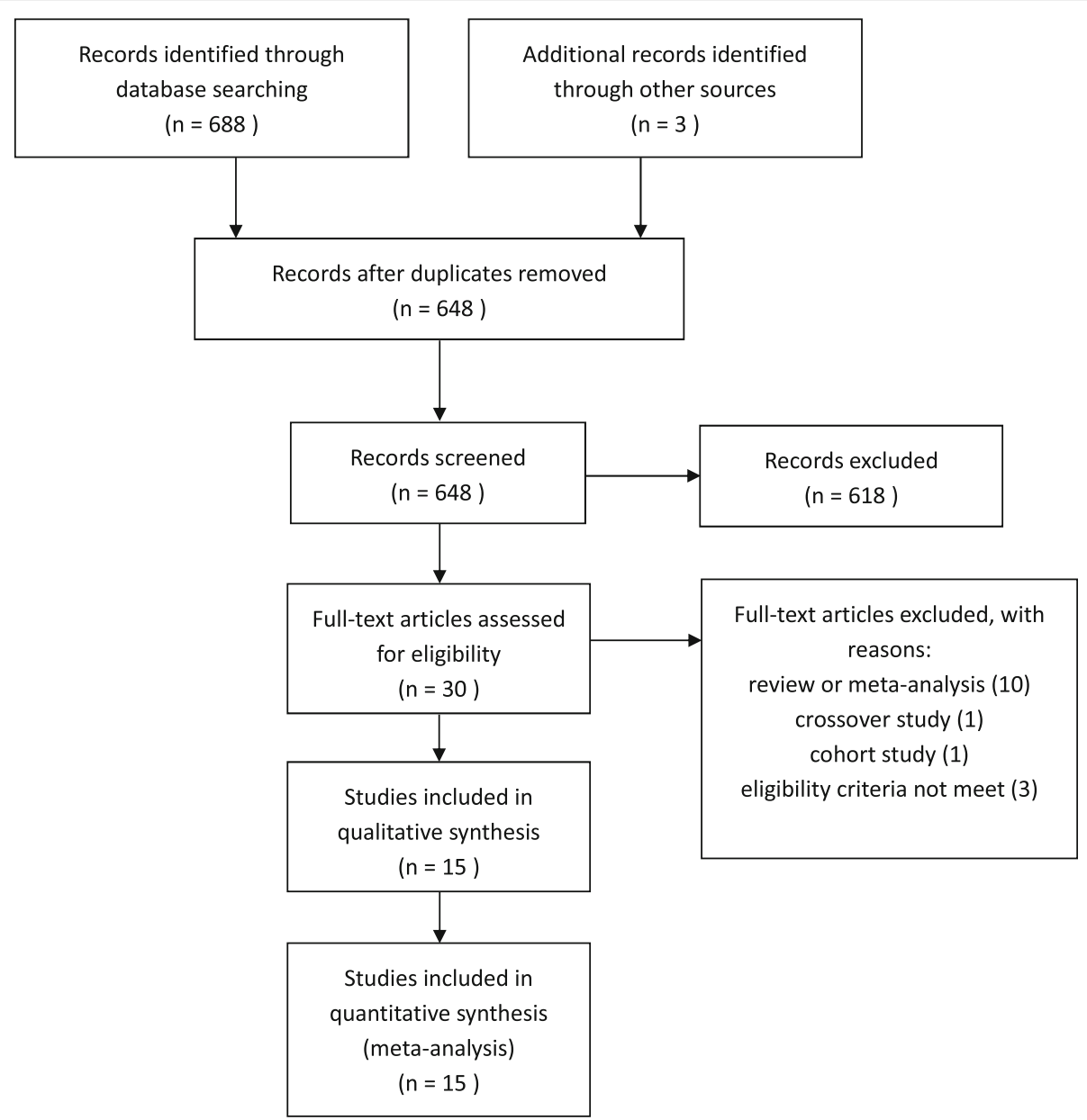

Fig. 1 Flow Diagram

patients, further details on these studies are listed in Table 1. All 15 studies were published between 1991 and 2019. All articles were intended to compare whether growth hormone could improve the IVF/ICSI outcomes of patients diagnosed with diminished ovarian reserve and/or poor ovarian response. The quality control evaluations of all studies are listed in Fig. 2.

\section{Live birth rate}

Eight studies [14, 17, 19, 20, 24, 25, 27, 29] including 789 patients (414 in the GH group and 375 in the control group) reported live birth rate. The meta-analysis indicated a statistically significant increase in the live birth rate in the GH group, compared to the control group (RR, 1.74; 95\% CI, 1.19-2.54; $p=0.004$ ), and no heterogeneity was observed between the studies $\left(\mathrm{I}^{2}=0 \% ; p=\right.$ 0.48), as shown in Fig. 3a.

\section{Clinical pregnancy rate}

Thirteen studies [14, 16-18, 20-25, 27-29] reported clinical pregnancy rate for 1304 patients (669 in the GH group and 635 in the control group). The meta-analysis (Fig. 3b) showed that GH addition could significantly increase the clinical pregnancy rate (RR, $1.65 ; 95 \% \mathrm{CI}$, $1.31-2.08 ; p<0.0001)$. There was low heterogeneity between studies $\left(\mathrm{I}^{2}=7 \% ; p=0.37\right)$.

\section{Miscarriage rate}

As shown in Fig. 4a, a total of 7 studies [14, 16-19, 22, 27] reported miscarriage rate. The meta-analysis indicated no significant difference in the miscarriage rates between the GH group and control group (RR, 1.02; 95\% CI, 0.61-1.70; $p=0.94)$. No heterogeneity was observed between the studies $\left(\mathrm{I}^{2}=0 \% ; p=0.92\right)$.

\section{Cycle cancellation rate}

With respect to the cancellation rate of IVF/ICSI cycles, 8 studies [14, 17, 20-23, 25, 28] including 841 patients (438 in the GH group and 403 in the control group) were eligible. The meta-analysis (Fig. $4 \mathrm{~b}$ ) revealed that $\mathrm{GH}$ addition group had significant lower cancellation rate (RR, 0.62; 95\% CI, 0.44-0.85; $p=0.003$ ) compared 
Table 1 Characteristics of the studies included

\begin{tabular}{|c|c|c|c|c|c|}
\hline Study & Intervention & $\mathrm{GH}$ & Control & Inclusion criteria & $\begin{array}{l}\text { Stimulation } \\
\text { protocol }\end{array}$ \\
\hline $\begin{array}{l}\text { Safdarian } \\
L \\
(2019) \\
{[20]}\end{array}$ & $\begin{array}{l}\text { GH } 2.5 \mathrm{mg} / \text { day from day } 8 \text { or } 0.1 \mathrm{mg} / \text { day } \\
\text { from previous cycle day } 3 \mathrm{f}\end{array}$ & 70 & 35 & $\begin{array}{l}\text { any two of three criteria to be met: age } \geq 40 \text { years; } \\
\text { oocytes } \leq 3 ; \mathrm{AFC}<5-7 \text { or } \mathrm{AMH}<0.5-1.1 \mathrm{ng} / \mathrm{ml}\end{array}$ & $\begin{array}{l}\text { GnRH antagonist } \\
\text { protocol }\end{array}$ \\
\hline $\begin{array}{l}\text { Norman } \\
\text { RJ } \\
(2019) \\
{[19]}\end{array}$ & GH 12 IU/day from day 1 of stimulation ${ }^{a}$ & 65 & 65 & oocytes $\leq 5 ;$ age $\leq 41 ; \mathrm{FSH} \leq 15 \mathrm{IU} / \mathrm{I}$ & $\begin{array}{l}\text { GnRH antagonist } \\
\text { protocol }\end{array}$ \\
\hline $\begin{array}{l}\text { Lee } Y X \\
(2019) \\
{[18]}\end{array}$ & $\mathrm{GH} 4,4,2 \mathrm{IU}$ for three successive days ${ }^{a}$ & 94 & 90 & age $\geq 40 ;$ oocytes $\leq 3 ; \mathrm{AFC}<5-7$ or $\mathrm{AMH}<0.5-1.1 \mathrm{ng} / \mathrm{ml}$ & $\begin{array}{l}\text { Long GnRH } \\
\text { agonist protocol }\end{array}$ \\
\hline $\begin{array}{l}\text { Dakhly } \\
\text { DMR } \\
\text { (2018) } \\
{[17]}\end{array}$ & $\mathrm{GH} 2.5 \mathrm{mg}$ from previous cycle day $21^{\mathrm{b}}$ & 120 & 120 & $\begin{array}{l}\text { any two of three criteria to be met: age } \geq 40 \text { years; } \\
\text { oocytes } \leq 3 \text {; AFC }<5-7 \text { or } \mathrm{AMH}<0.5-1.1 \mathrm{ng} / \mathrm{ml}\end{array}$ & $\begin{array}{l}\text { Long GnRH } \\
\text { agonist protocol }\end{array}$ \\
\hline $\begin{array}{l}\text { Choe SA } \\
(2018) \\
{[16]}\end{array}$ & $\begin{array}{l}\text { GH } 20 \text { mg three times at mid-luteal, late lu- } \\
\text { teal, and menstrual cycle day } 2^{c}\end{array}$ & 62 & 65 & age $\geq 40$; oocytes $\leq 3$; AFC $<5-7$ or $\mathrm{AMH}<0.5-1.1 \mathrm{ng} / \mathrm{ml}$ & $\begin{array}{l}\text { GnRH antagonist } \\
\text { protocol }\end{array}$ \\
\hline $\begin{array}{l}\text { Bassiouny } \\
\text { YA } \\
(2016) \\
{[14]}\end{array}$ & GH 2.5 mg from day 6 of stimulation ${ }^{b}$ & 68 & 73 & $\begin{array}{l}\text { any two of three criteria to be met: age } \geq 40 \text { years; } \\
\text { oocytes } \leq 3 \text {; AFC }<5-7 \text { or } \mathrm{AMH}<0.5-1.1 \mathrm{ng} / \mathrm{ml}\end{array}$ & $\begin{array}{l}\text { GnRH antagonist } \\
\text { protocol }\end{array}$ \\
\hline $\begin{array}{l}\text { Bayoumi } \\
\text { YA } \\
(2015) \\
{[21]}\end{array}$ & GH $2.5 \mathrm{mg}$ from day 6 of stimulation ${ }^{f}$ & 84 & 88 & $\begin{array}{l}\text { any two of three criteria to be met: age } \geq 40 \text { years; } \\
\text { oocytes } \leq 3 \text {; AFC }<5-7 \text { or } \mathrm{AMH}<0.5-1.1 \mathrm{ng} / \mathrm{ml}\end{array}$ & $\begin{array}{l}\text { microflare } \\
\text { protoco }\end{array}$ \\
\hline $\begin{array}{l}\text { Eftekhar } \\
\text { M } \\
(2013) \\
{[22]}\end{array}$ & GH 4 IU/day from previous cycle day $21^{c}$ & 40 & 42 & failed IVF cycles $\geq 1$; oocytes $\leq 3$ & $\begin{array}{l}\text { GnRH antagonist } \\
\text { protocol }\end{array}$ \\
\hline $\begin{array}{l}\text { Kucuk T } \\
(2008) \\
{[23]}\end{array}$ & $\mathrm{GH} 12 \mathrm{IU} /$ day from previous cycle day $21^{\mathrm{b}}$ & 31 & 30 & $\begin{array}{l}\text { responded poorly to high dose gonadotropin in first } \\
\text { cycle }\end{array}$ & $\begin{array}{l}\text { GnRH agonist } \\
\text { long protocol }\end{array}$ \\
\hline $\begin{array}{l}\text { Tesarik J } \\
(2005) \\
{[24]}\end{array}$ & GH $8 \mathrm{IU} /$ day from day 7 of stimulation ${ }^{a}$ & 50 & 50 & age $41-44$ years & $\begin{array}{l}\text { GnRH agonist } \\
\text { long protocol }\end{array}$ \\
\hline $\begin{array}{l}\text { Suikkari A } \\
(1996) \\
{[25]}\end{array}$ & $\begin{array}{l}\text { GH } 4 \mathrm{IU} / \text { day or } 12 \mathrm{IU} / \text { day from menstrual } \\
\text { cycle day } 3 \text { d }\end{array}$ & 16 & 6 & oocytes $\leq 2$ or $\geq 48$ amples of hMG & $\begin{array}{l}\text { GnRH-a flare up } \\
\text { protocol }\end{array}$ \\
\hline $\begin{array}{l}\text { Dor J } \\
(1995) \\
{[26]}\end{array}$ & GH $18 \mathrm{IU}$ on days $2,4,6$ and 8 of the cycle ${ }^{e}$ & 7 & 7 & $\begin{array}{l}17-\beta \text { oestradiol on } \mathrm{hCG} \text { day }<501 \mathrm{pg} / \mathrm{ml} \text {; follicles } \leq 4 \\
\text { oocytes } \leq 3\end{array}$ & $\begin{array}{l}\text { GnRH agonist } \\
\text { short protocol }\end{array}$ \\
\hline $\begin{array}{l}\text { Bergh C } \\
(1994) \\
{[28]}\end{array}$ & GH $0.1 \mathrm{IU} / \mathrm{kg}$ during stimulation ${ }^{d}$ & 9 & 9 & failed IVF attempts $\geq 2$, oocytes $<5$, age $25-38$ years & $\begin{array}{l}\text { GnRH agonist } \\
\text { long protocol }\end{array}$ \\
\hline $\begin{array}{l}\text { Zhuang } \\
\text { GL } \\
(1994) \\
{[27]}\end{array}$ & GH $12 \mathrm{IU}$ on alternate days ${ }^{\mathrm{a}}$ & 12 & 15 & previous sub-optimal response & $\begin{array}{l}\text { GnRH agonist } \\
\text { long protocol }\end{array}$ \\
\hline $\begin{array}{l}\text { Owen EJ } \\
(1991) \\
{[29]}\end{array}$ & $\begin{array}{l}\text { GH } 24 \text { IU on alternate days during } \\
\text { stimulation }^{\text {b }}\end{array}$ & 13 & 12 & oocytes $\leq 6$, embryos $\leq 3$ & $\begin{array}{l}\text { microflare } \\
\text { protoco }\end{array}$ \\
\hline
\end{tabular}

${ }^{a}$ Participants administrated with GH (Saizen, Merck Serono)

${ }^{b}$ Participants administrated with GH (Norditropin, Novo Nordisk)

c Participants administrated with GH (Eutropin, LG)

${ }^{d}$ Participants administrated with GH (Genotropin, Kabi pharmacia)

e Participants administrated with GH (Bio-Gropin; Bio-Technology General)

${ }^{f}$ The product name of $\mathrm{GH}$ was not mentioned 


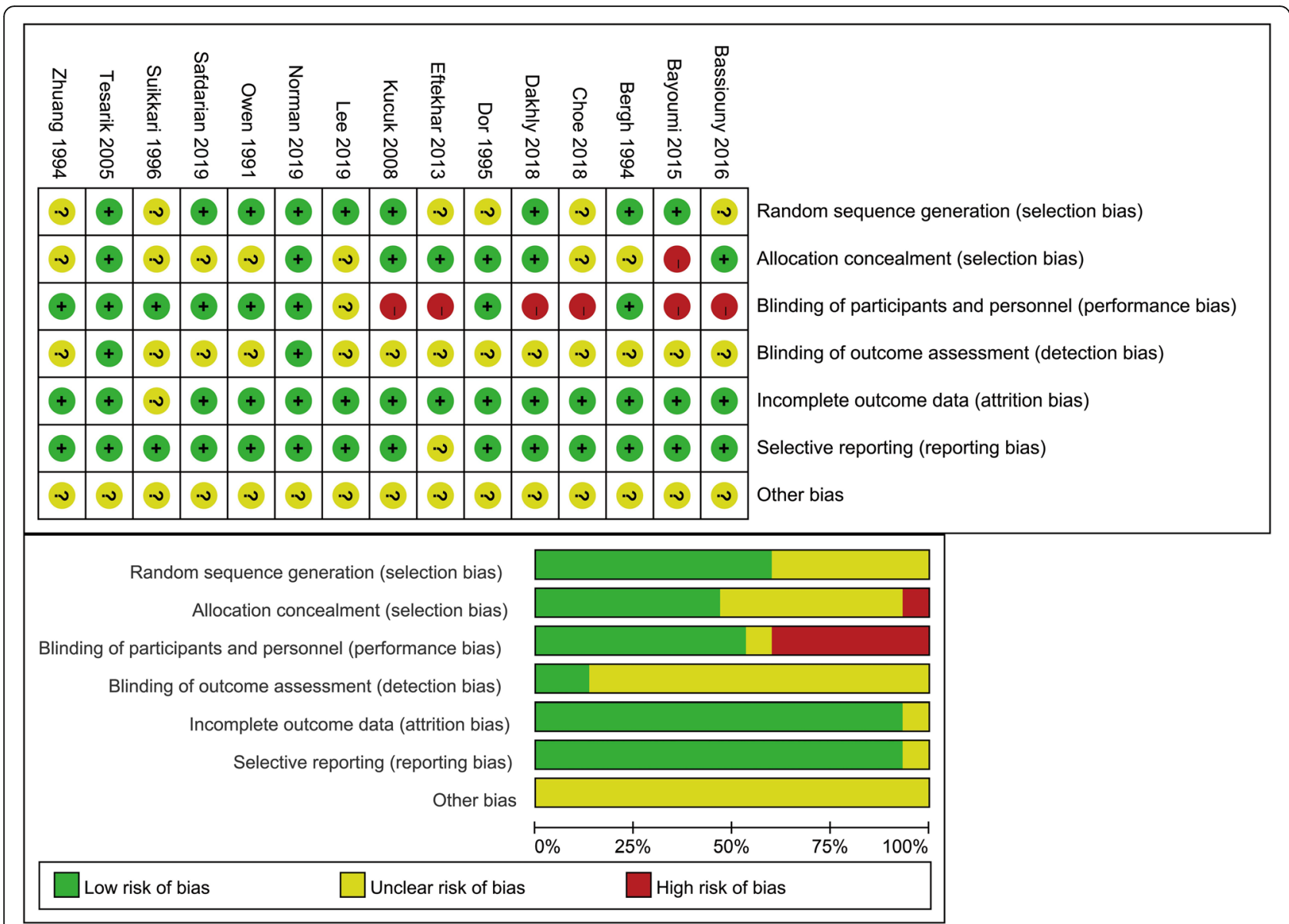

Fig. 2 Quality control evaluations of included studies? = unclear, $+=$ low risk,-=high risk

to control group. The heterogeneity between studies was low $\left(\mathrm{I}^{2}=20 \% ; p=0.27\right)$.

\section{Number of retrieved oocytes}

A total of 13 studies reported number of retrieved oocytes, two of which $[25,26]$ lacked standard deviation of data, and one study [29] lacked the specific data of retrieved oocyte number. Finally, ten studies $[14,16-18$, 20-22, 24, 27, 28] including 1196 patients (609 in the GH group and 587 in the control group) were eligible for the meta-analysis. As shown in Fig. 4c, the number of retrieved oocytes was significantly increased in $\mathrm{GH}$ group, compared to the control group (SMD, 0.72; 95\% CI, 0.28-1.16; $p=0.001$ ). However, significant heterogeneity was detected among these studies $\left(\mathrm{I}^{2}=92 \% ; p<\right.$ 0.00001), therefore, the random effects model was performed.

\section{Total dose of gonadotropin}

A total of 12 studies reported total dose of gonadotropin, three of which $[25,26,28]$ lacked standard deviation of data, and one study [29] didn't report the specific data of gonadotropin dosage. The meta-analysis finally included 8 studies [14, 17, 19-24] for 1031 patients (528 in the GH group and 503 in the control group). The result indicated a significant decrease in the gonadotropin dosage with the administration of $\mathrm{GH}$ (SMD,-1.05 95\% CI, - $1.62--0.49 ; p=0.0003$ ). The random effects model was performed because of the high heterogeneity among these studies $\left(\mathrm{I}^{2}=94 \% ; p<\right.$ 0.00001), as shown in Fig. 4d.

\section{Publication bias}

Funnel plots were used to evaluate the potential publication bias. The funnel plot for the outcome of clinical pregnancy rate was asymmetric, as each point was scattered in Fig. 5. The potential publication bias could not be excluded.

\section{Discussion}

The success of IVF/ICSI cycles is highly dependent on the number of retrieved oocytes that form qualified embryos for transfer. Low number of mature oocyte due to decreased ovarian reserve is a success-limiting factor for 


\begin{tabular}{|c|c|c|c|c|c|c|c|c|c|c|c|}
\hline \multirow{2}{*}{ Study or Subgroup } & \multirow{2}{*}{$\begin{array}{r}\mathbf{G H} \\
\text { Events } \\
10\end{array}$} & Total & \multicolumn{2}{|c|}{ Control } & Weight & \multirow{2}{*}{$\begin{array}{c}\begin{array}{c}\text { Risk Ratio } \\
\text { M-H, Fixed. } 95 \% \mathrm{Cl}\end{array} \\
1.34[0.56,3.20]\end{array}$} & \multicolumn{5}{|c|}{$\begin{array}{c}\text { Risk Ratio } \\
\text { M-H, Fixed, 95\% Cl }\end{array}$} \\
\hline & & 68 & 8 & 73 & $20.6 \%$ & & & & & $=$ & \\
\hline Dakhly 2018 & 21 & 120 & 17 & 120 & $45.4 \%$ & $1.24[0.69,2.22]$ & & & & - & \\
\hline Norman 2019 & 9 & 65 & 7 & 64 & $18.8 \%$ & $1.27[0.50,3.19]$ & & & & +- & \\
\hline Owen 1991 & 4 & 13 & 0 & 12 & $1.4 \%$ & $8.36[0.50,140.56]$ & & & & & \\
\hline Safdarian 2019 & 5 & 70 & 0 & 35 & $1.8 \%$ & $5.58[0.32,98.09]$ & & & & & \\
\hline Suikkari 1996 & 2 & 16 & 0 & 6 & $1.9 \%$ & $2.06[0.11,37.64]$ & & & & & \\
\hline Tesarik 2005 & 11 & 50 & 2 & 50 & $5.3 \%$ & $5.50[1.28,23.56]$ & & & & & \\
\hline Zhuang 1994 & 4 & 12 & 2 & 15 & $4.7 \%$ & $2.50[0.55,11.41]$ & & & & & \\
\hline Total $(95 \% \mathrm{Cl})$ & & 414 & & 375 & $100.0 \%$ & $1.74[1.19,2.54]$ & & & & $\gamma$ & \\
\hline Total events & 66 & & 36 & & & & & & & & \\
\hline $\begin{array}{l}\text { Heterogeneity: } \mathrm{Chi}^{2}= \\
\text { Test for overall effect: }\end{array}$ & $\begin{array}{l}3.57, \mathrm{df}=7 \\
Z=2.88(P\end{array}$ & $\begin{array}{l}7(P=0 \\
P=0.00\end{array}$ & $\begin{array}{l}0.48) ; 1^{2}= \\
04)\end{array}$ & $0 \%$ & & & 0.001 & & $\begin{array}{cc}0.1 & 1 \\
\text { Control }\end{array}$ & ${ }^{1} \mathrm{GH}$ & 1000 \\
\hline A & & & & & & & & & & & \\
\hline Study or Subgroup & $\begin{array}{r}\text { GH } \\
\text { Events }\end{array}$ & Total & $\begin{array}{c}\text { Contr } \\
\text { Events }\end{array}$ & $\begin{array}{l}\text { ol } \\
\text { Total }\end{array}$ & Weight & $\begin{array}{c}\text { Risk Ratio } \\
\text { M-H. Fixed, } 95 \% \mathrm{Cl}\end{array}$ & & & $\begin{array}{r}\text { Risk } \\
\text { M-H, Fixe }\end{array}$ & $\begin{array}{l}\text { Ratio } \\
\text { ed. } 95 \% \mathrm{Cl}\end{array}$ & \\
\hline Bassiouny 2016 & 15 & 68 & 11 & 73 & $11.3 \%$ & $1.46[0.72,2.96]$ & & & & $=$ & \\
\hline Bayoumi 2015 & 24 & 84 & 15 & 88 & $15.6 \%$ & $1.68[0.95,2.97]$ & & & & $\rightarrow$ & \\
\hline Bergh 1994 & 3 & 9 & 2 & 9 & $2.1 \%$ & $1.50[0.32,6.94]$ & & & & . & \\
\hline Choe 2018 & 6 & 62 & 11 & 65 & $11.4 \%$ & $0.57[0.23,1.45]$ & & & & - & \\
\hline Dakhly 2018 & 29 & 120 & 23 & 120 & $24.4 \%$ & $1.26[0.78,2.05]$ & & & & + & \\
\hline Eftekhar 2013 & 5 & 40 & 5 & 42 & $5.2 \%$ & $1.05[0.33,3.35]$ & & & & & \\
\hline Kucuk 2008 & 10 & 31 & 5 & 30 & $5.4 \%$ & $1.94[0.75,5.00]$ & & & & & \\
\hline Lee 2019 & 30 & 94 & 15 & 90 & $16.3 \%$ & $1.91[1.11,3.31]$ & & & & $\longrightarrow$ & \\
\hline Owen 1991 & 4 & 13 & 1 & 12 & $1.1 \%$ & $3.69[0.48,28.57]$ & & & & & \\
\hline Safdarian 2019 & 13 & 70 & 1 & 35 & $1.4 \%$ & $6.50[0.89,47.70]$ & & & & & \\
\hline Suikkari 1996 & 2 & 16 & 0 & 6 & $0.8 \%$ & $2.06[0.11,37.64]$ & & & & & \\
\hline Tesarik 2005 & 13 & 50 & 3 & 50 & $3.2 \%$ & $4.33[1.31,14.28]$ & & & & & \\
\hline Zhuang 1994 & 5 & 12 & 2 & 15 & $1.9 \%$ & $3.13[0.73,13.37]$ & & & & & \\
\hline Total $(95 \% \mathrm{Cl})$ & & 669 & & 635 & $100.0 \%$ & $1.65[1.31,2.08]$ & & & & 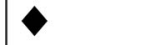 & \\
\hline Total events & 159 & & 94 & & & & & & & & \\
\hline $\begin{array}{l}\text { Heterogeneity: } \mathrm{Chi}^{2}= \\
\text { Test for overall effect: }\end{array}$ & $\begin{array}{l}12.93, \mathrm{df}= \\
Z=4.21(F\end{array}$ & $\begin{array}{l}12(P= \\
P<0.00\end{array}$ & $\begin{array}{l}=0.37) ; 1^{2} \\
001)\end{array}$ & $=7 \%$ & & & 0.01 & 0.1 & Control $^{1}$ & ${ }^{1} \mathrm{GH}$ & 100 \\
\hline
\end{tabular}

IVF/ICSI cycle outcomes [30]. Improving the IVF/ICSI outcomes is a challenge to infertility experts. Various efforts have been tried for improving IVF/ICSI outcomes of POR patients, including growth hormone administration. However, the effect of GH on POR patients has not been precisely determined yet.

Therefore, this meta-analysis was performed to provide a more precise estimate of the effect of GH supplementation for POR patients undergoing IVF/ICSI. Our meta-analysis included fifteen RCTs, and the results indicated that GH supplementation is associated with higher live birth rate in IVF/ICSI patients with POR. More oocytes were retrieved in the GH group for POR women in the IVF/ICSI cycle. GH supplementation might improve clinical pregnancy rate in our study, however, the potential publication bias for this outcome could not be excluded. Besides, the cancellation rate and gonadotropin dosage were decreased with the administration of $\mathrm{GH}$, and no differences were observed in the miscarriage rate between the $\mathrm{GH}$ and control groups.

A previous meta-analysis done by Li et al. in 2017 [31] suggested that $\mathrm{GH}$ application significantly improved clinical pregnancy rate, live birth rate, collected oocytes number, meanwhile decreased cancelled cycles rate and dose of gonadotropin. Comparing to this study, five new RCTs $[16-20,26,27]$ were included in our metaanalysis. The results of the two studies were similar. Additionally, our meta-analysis reported no significant difference in miscarriage rate between the $\mathrm{GH}$ and control groups, and Li et al. demonstrated more MII oocyte number, higher $E_{2}$ on HCG day, no influence on implantation rate and fertilization rate with $\mathrm{GH}$ administration. Another meta-analysis [32] also indicated that GH supplementation improved clinical pregnancy rate and live birth rate. In a recent systematic review and 


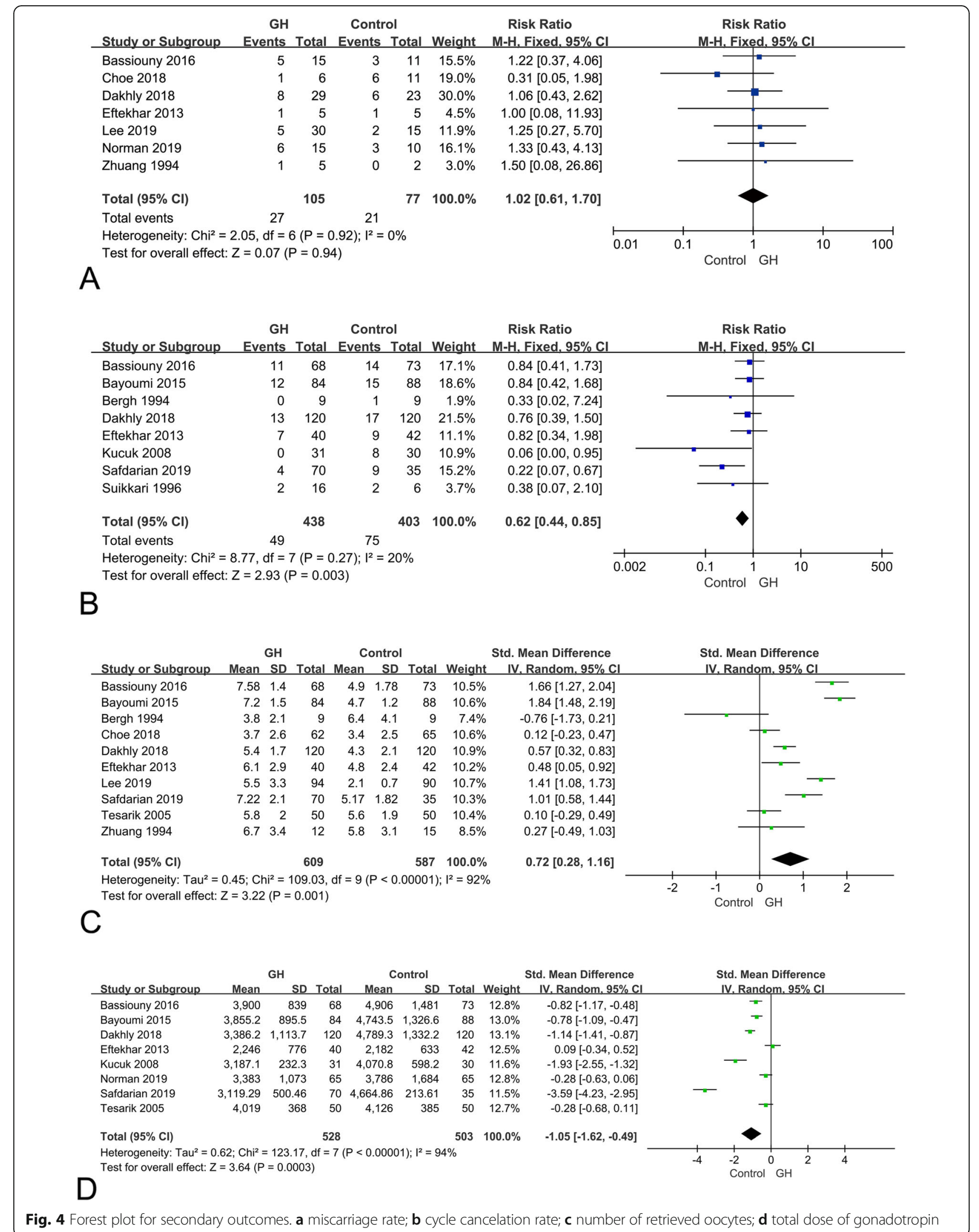




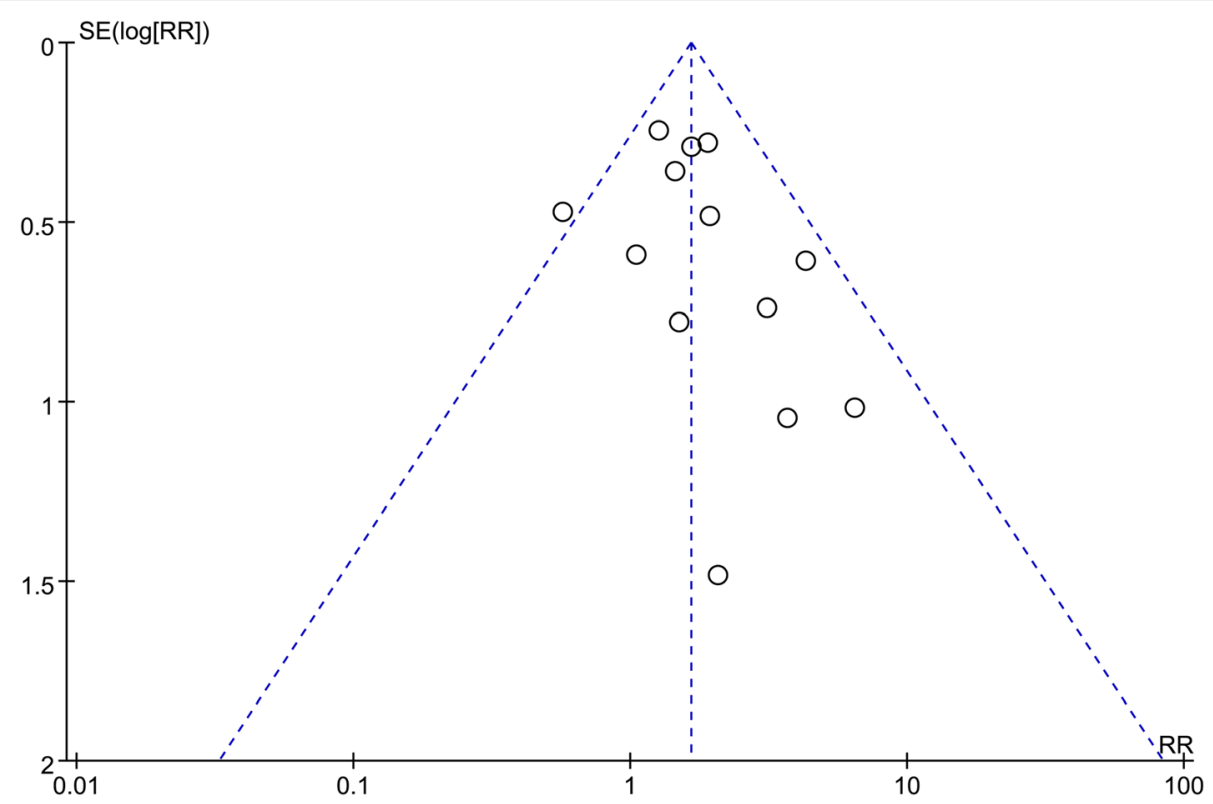

Fig. 5 Funnel plot of the studies represented in the meta-analysis

network meta-analysis [33] comparing the effectiveness of various adjuvant treatment options to POR patients, GH treatment was reported to resulting in higher number of oocyte retrieved and lower dosages of gonadotropins for ovarian stimulation. These results were similar to our study. The Cochrane review published in 2010 [15] also demonstrated a statistically significant difference in both live birth rates and pregnancy rates favouring the use of adjuvant growth hormone in IVF protocols in POR women, however, the Cochrane review showed no significant difference in collected oocytes number with GH supplementation, which was different from our study. And a meta-analysis including 6 randomized controlled trials and 5 controlled clinical trials [34] reported that the clinical pregnancy rates between $\mathrm{GH}$ group and control group were similar in POR women in IVF/ICSI cycles, the difference may be associated with different included article type or different analysis methods.

The present meta-analysis demonstrates that GH supplementation in IVF protocol was an adjuvant treatment benefit to the IVF outcomes in patients with POR, the detailed mechanisms of which is still being investigated. GH can attach growth hormone receptors on oocytes, thus influencing their function. Previous studies have shown that GH supplementation might promote nuclear maturation of denuded human oocytes [35-37], improve oocyte quality by stimulating the growth and function of granulose cells [38, 39], improve reactivity of ovary [40] and endometrial receptivity [5], which might contribute to better IVF outcome.
Our meta-analysis included numbers of prospectively designed RCTs, and involved a large amount of patients, which improves the statistical power. However, the meta-analysis has several limitations. First of all, although there was low heterogeneity in the analyses of primary outcomes, the heterogeneity between the studies was found on number of retrieved oocytes and total dose of gonadotropin, the sources of heterogeneity between the studies may be related to the different definition of POR, stimulation protocol, and GH treatment method. Secondly, some included studies had relatively small sample sizes. This may have influenced the validity and reliability of our conclusions. Finally, not all included RCTs had strict methods of randomization, blinding, allocation concealment, missing data treatment, studies chosen did not have data for all outcomes or lacked data for some outcomes, and the potential publication bias for outcome clinical pregnancy rate could not be excluded in the study, which may affect the conclusions.

Data from this meta-analysis provides support for $\mathrm{GH}$ supplementation in IVF/ICSI cycles. GH leaded to higher live birth rate, since live birth is the ultimate endpoint and primary outcome of infertility interventions, it might be a main benefit to POR women. Adjuvant treatment with GH decreased cycle cancellation rate, which helps shorten the treatment time of IVF. GH supplementation did not increase miscarriage rate. Moreover, no sever adverse event was reported in the RCTs included in our meta-analysis except that Norman reported one trisomy 21 and one patent ductus arteriosus in GH group [19], and the Cochrane review [15] 
indicated that the use of growth hormone adjuvant in IVF did not increase adverse events in women who are considered poor responders. Therefore the GH adjuvant treatment seems to be beneficial and relatively safe. However, there has been no standard protocol regarding $\mathrm{GH}$ addition time and dosage so far. Studies have shown that GH may contribute to insulin resistance and may be in relation with cancer [39]. In view of this, further studies are needed to establish the threshold dosage and the administration protocol of $\mathrm{GH}$.

\section{Conclusion}

In conclusion, the results of this meta-analysis suggested that GH supplementation might improve live birth rate, clinical pregnancy rate and retrieved oocytes number for poor ovarian responders who are undergoing IVF/ ICSI. Besides, GH decreased cancelled cycles rate and dose of Gonadotropin for POR women, meanwhile having no influence in the miscarriage rate. However, further largescale RCTs should be performed to determine the utility of GH adjuvant therapy in the treatment of women with poor ovarian response.

\section{Supplementary information}

Supplementary information accompanies this paper at https://doi.org/10. 1186/s12958-020-00632-w.

Additional file 1.

\section{Acknowledgements}

We gratefully acknowledge Cong Sui for reviewing this manuscript.

\section{Authors' contributions}

PWY: Project development, data collection, data analysis and manuscript writing. RXW: Data collection and data analysis. HWZ: Project development, manuscript editing and manuscript revising. The author(s) read and approved the final manuscript.

\section{Funding}

No funding was received.

\section{Availability of data and materials}

Please contact author for data requests.

Ethics approval and consent to participate

Not applicable.

\section{Consent for publication}

Not applicable.

\section{Competing interests}

The authors declare that they have no competing interests.

Received: 8 April 2020 Accepted: 21 July 2020

Published online: 29 July 2020

\section{References}

1. Ozkan ZS. Ovarian stimulation modalities in poor responders. Turk J Med Sci. 2019;49:959-62.

2. Yilmaz N, Uygur D, Inal H, Gorkem U, Cicek N, Mollamahmutoglu L. Dehydroepiandrosterone supplementation improves predictive markers for diminished ovarian reserve: serum $\mathrm{AMH}$, inhibin $\mathrm{B}$ and antral follicle count. Eur J Obstet Gynecol Reprod Biol. 2013;169:257-60.

3. Zhang M, Niu W, Wang Y, Xu J, Bao X, Wang L, Du L, Sun Y. Dehydroepiandrosterone treatment in women with poor ovarian response undergoing IVF or ICSI: a systematic review and meta-analysis. J Assist Reprod Genet. 2016:33:981-91.

4. Ferraretti AP, La Marca A, Fauser BC, Tarlatzis B, Nargund G, Gianaroli L. Definition EwgoPOR: ESHRE consensus on the definition of 'poor response' to ovarian stimulation for in vitro fertilization: the Bologna criteria. Hum Reprod. 2011;26:1616-24.

5. Altmae S, Mendoza-Tesarik R, Mendoza C, Mendoza N, Cucinelli F, Tesarik J. Effect of growth hormone on uterine receptivity in women with repeated implantation failure in an oocyte donation program: a randomized controlled trial. J Endocr Soc. 2018;2:96-105.

6. Sirotkin AV. Control of reproductive processes by growth hormone: extraand intracellular mechanisms. Vet J. 2005;170:307-17.

7. Lanzone A, Fortini A, Fulghesu AM, Soranna L, Caruso A, Mancuso S. Growth hormone enhances estradiol production follicle-stimulating hormoneinduced in the early stage of the follicular maturation. Fertil Steril. 1996;66: 948-53.

8. Weall BM, Al-Samerria S, Conceicao J, Yovich JL, Almahbobi G. A direct action for $\mathrm{GH}$ in improvement of oocyte quality in poor-responder patients. Reproduction. 2015;149:147-54.

9. Magalhaes DM, Duarte AB, Araujo VR, Brito IR, Soares TG, Lima IM, Lopes CA, Campello CC, Rodrigues AP, Figueiredo JR. In vitro production of a caprine embryo from a preantral follicle cultured in media supplemented with growth hormone. Theriogenology. 2011;75:182-8.

10. Kobayashi J, Mizunuma H, Kikuchi N, Liu X, Andoh K, Abe Y, Yokota H, Yamada K, Ibuki Y, Hagiwara H. Morphological assessment of the effect of growth hormone on preantral follicles from 11-day-old mice in an in vitro culture system. Biochem Biophys Res Commun. 2000;268:36-41.

11. Adams NR, Briegel JR. Multiple effects of an additional growth hormone gene in adult sheep. J Anim Sci. 2005;83:1868-74.

12. Lattes K, Brassesco M, Gomez M, Checa MA. Low-dose growth hormone supplementation increases clinical pregnancy rate in poor responders undergoing in vitro fertilisation. Gynecol Endocrinol. 2015;31:565-8.

13. Chu K, Pang W, Sun N, Zhang Q, Li W. Outcomes of poor responders following growth hormone co-treatment with IVF/ICSI mild stimulation protocol: a retrospective cohort study. Arch Gynecol Obstet. 2018;297:1317-21.

14. Bassiouny YA, Dakhly DMR, Bayoumi YA, Hashish NM. Does the addition of growth hormone to the in vitro fertilization/intracytoplasmic sperm injection antagonist protocol improve outcomes in poor responders? A randomized, controlled trial. Fertil Steril. 2016;105:697-702.

15. Duffy JM, Ahmad G, Mohiyiddeen L, Nardo LG, Watson A. Growth hormone for in vitro fertilization. Cochrane Database Syst Rev. 2010;2010(1):CD000099.

16. Choe SA, Kim MJ, Lee HJ, Kim J, Chang EM, Kim JW, Park HM, Lyu SW, Lee WS, Yoon TK, Kim YS. Increased proportion of mature oocytes with sustainedrelease growth hormone treatment in poor responders: a prospective randomized controlled study. Arch Gynecol Obstet. 2018;297:791-6.

17. Dakhly DMR, Bassiouny YA, Bayoumi YA, Hassan MA, Gouda HM, Hassan AA. The addition of growth hormone adjuvant therapy to the long down regulation protocol in poor responders undergoing in vitro fertilization: randomized control trial. Eur J Obstet Gynecol Reprod Biol. 2018;228:161-5.

18. Lee $Y X$, Shen MS, Tzeng CR. Low dose growth hormone adjuvant treatment with ultra-long ovarian stimulation protocol in poor responders showed non-inferior pregnancy outcome compared with Normal responders. Front Endocrinol (Lausanne). 2019;10:892.

19. Norman RJ, Alvino H, Hull LM, Mol BW, Hart RJ, Kelly TL, Rombauts L. Human growth hormone for poor responders: a randomized placebocontrolled trial provides no evidence for improved live birth rate. Ann Rheum Dis. 2019;38:908-15.

20. Safdarian L, Aghahosseini M, Alyasin A, Samaei Nouroozi A, Rashidi S, Shabani Nashtaei M, Najafian A, Lak P. Growth hormone (GH) improvement of ovarian responses and pregnancy outcome in poor ovarian responders: a randomized study. Asian Pac J Cancer Prev. 2019;20:2033-7.

21. Bayoumi YA, Dakhly DM, Bassiouny YA, Hashish NM. Addition of growth hormone to the microflare stimulation protocol among women with poor ovarian response. Int J Gynaecol Obstet. 2015;131:305-8.

22. Eftekhar M, Aflatoonian A, Mohammadian F, Eftekhar T. Adjuvant growth hormone therapy in antagonist protocol in poor responders undergoing assisted reproductive technology. Arch Gynecol Obstet. 2013;287:1017-21. 
23. Kucuk T, Kozinoglu H, Kaba A. Growth hormone co-treatment within a $\mathrm{GnRH}$ agonist long protocol in patients with poor ovarian response: a prospective, randomized, clinical trial. J Assist Reprod Genet. 2008;25:123-7.

24. Tesarik J, Hazout A, Mendoza C. Improvement of delivery and live birth rates after ICSI in women aged $>40$ years by ovarian co-stimulation with growth hormone. Hum Reprod. 2005;20:2536-41.

25. Suikkari A, MacLachlan V, Koistinen R, Seppala M, Healy D. Double-blind placebo controlled study: human biosynthetic growth hormone for assisted reproductive technology. Fertil Steril. 1996;65:800-5.

26. Dor J, Seidman DS, Amudai E, Bider D, Levran D, Mashiach S. Adjuvant growth hormone therapy in poor responders to in-vitro fertilization: a prospective randomized placebo-controlled double-blind study. Hum Reprod. 1995;10:40-3.

27. Zhuang GL, Wong SX, Zhou CQ. The effect of co-administration of low dosage growth hormone and gonadotropin for ovarian hyperstimulation in vitro fertilization and embryo transfer. Zhonghua Fu Chan Ke Za Zhi. 1994;29:471-4 510.

28. Bergh C, Hillensjo T, Wikland M, Nilsson L, Borg G, Hamberger L. Adjuvant growth hormone treatment during in vitro fertilization: a randomized, placebo-controlled study. Fertil Steril. 1994;62:113-20.

29. Owen EJ, West C, Mason BA, Jacobs HS. Co-treatment with growth hormone of sub-optimal responders in IVF-ET. Hum Reprod. 1991;6:524-8.

30. Timeva T, Milachich T, Antonova I, Arabaji T, Shterev A, Omar HA. Correlation between number of retrieved oocytes and pregnancy rate after in vitro fertilization/intracytoplasmic sperm infection. ScientificWorldJournal. 2006;6:686-90.

31. Li $X L$, Wang $L$, LV F, Huang XM, Wang LP, Pan Y, Zhang XM. The influence of different growth hormone addition protocols to poor ovarian responders on clinical outcomes in controlled ovary stimulation cycles: a systematic review and meta-analysis. Medicine (Baltimore). 2017;96:e6443.

32. Jeve YB, Bhandari HM. Effective treatment protocol for poor ovarian response: a systematic review and meta-analysis. J Hum Reprod Sci. 2016;9: 70-81.

33. Zhang Y, Zhang C, Shu J, Guo J, Chang HM, Leung PCK, Sheng JZ, Huang H. Adjuvant treatment strategies in ovarian stimulation for poor responders undergoing IVF: a systematic review and network meta-analysis. Hum Reprod Update. 2020;26(2)247-63.

34. Yu X, Ruan J, He LP, Hu W, Xu Q, Tang J, Jiang J, Han J, Peng YF. Efficacy of growth hormone supplementation with gonadotrophins in vitro fertilization for poor ovarian responders: an updated meta-analysis. Int J Clin Exp Med. 2015;8:4954-67.

35. Abir R, Garor R, Felz C, Nitke S, Krissi H, Fisch B. Growth hormone and its receptor in human ovaries from fetuses and adults. Fertil Steril. 2008;90: 1333-9.

36. Menezo YJ, el Mouatassim S, Chavrier M, Servy EJ, Nicolet B. Human oocytes and preimplantation embryos express mRNA for growth hormone receptor. Zygote. 2003;11:293-7.

37. Menezo YJ, Nicollet B, Rollet J, Hazout A. Pregnancy and delivery after in vitro maturation of naked ICSI-GV oocytes with GH and transfer of a frozen thawed blastocyst: case report. J Assist Reprod Genet. 2006;23:47-9.

38. Bachelot A, Monget P, Imbert-Bollore P, Coshigano K, Kopchick JJ, Kelly PA, Binart N. Growth hormone is required for ovarian follicular growth. Endocrinology. 2002;143:4104-12.

39. Hull KL, Harvey S. Growth hormone and reproduction: a review of endocrine and autocrine/paracrine interactions. Int J Endocrinol. 2014;2014: 234014

40. Ob'edkova K, Kogan I, Krikheli I, Dzhemlikhanova L, Muller V, Mekina I, Lesik E, Komarova E, Mazilina M, Niauri D, et al. Growth hormone co-treatment in IVF/ICSI cycles in poor responders. Gynecol Endocrinol. 2017;33:15-7.

\section{Publisher's Note}

Springer Nature remains neutral with regard to jurisdictional claims in published maps and institutional affiliations.

Ready to submit your research? Choose BMC and benefit from:

- fast, convenient online submission

- thorough peer review by experienced researchers in your field

- rapid publication on acceptance

- support for research data, including large and complex data types

- gold Open Access which fosters wider collaboration and increased citations

- maximum visibility for your research: over $100 \mathrm{M}$ website views per year

At BMC, research is always in progress.

Learn more biomedcentral.com/submissions 